\section{Conclusions}

The finding that death rates in young offenders exceed those in groups with even higher rates of psychiatric and behavioural disorders indicates that social disadvantage and marginalisation of this group may have played an additional part in many of the deaths. The findings have important implications for social policies for young offenders. On one hand the high rates of deaths due to drug overdose and suicide indicate a need for a better response to prevalent problems of drug misuse and psychiatric disorder. On the other hand, we also need to develop strategies effective in the social reintegration of young offenders. Health practitioners are likely to have an essential role in the implementation of such responses.

Contributors: See bmj.com

Funding: National Health and Medical Research Council Competing Standard Project Grant 105422. The guarantor accepts full responsibility for the conduct of the study, had access to the data, and controlled the decision to publish.

Competing interests: None declared.

Ethical approval: Ethics committees of the Royal Children's Hospital, Victorian Departments of Human Services and Justice, and the Australian Institute of Health and Welfare.

1 Stattin H, Romelsjo A. Adult mortality in the light of criminality, substance abuse, and behavioural and family-risk factors in adolescence Crim Bee abuse, and behavioural and fam

2 Yaeger CA, Otnow Lewis D. Mortality in a group of formerly incarcerated juvenile delinquents. Am J Psychiatry 1990;147:612-4

Rydelius PA. The development of antisocial behaviour and sudden violent death. Acta Psychiatr Scand 1988;77:398-403.

4 Rothman KJ, Greenland S. Modern epidemiology. Philadelphia: LippincottRaven, 1998.

5 Hall W, Degenhardt L, Lynskey M. Trends in opioid overdose and suicide mortality in young adults in Australia 1964-97. Sydney, NSW: University of New South Wales, 1999. (NDARC Technical Report No 67.)

\section{What is already known on this topic}

Socially excluded young people experience high levels of psychiatric disorder, childhood abuse, and substance dependence

Death rates in antisocial and offending young people are high

\section{What this study adds}

Young male offenders were nine times more likely and female offenders were 40 times more likely to die than young people in the general population

Drug related causes, suicide, and non-intentional injury were the leading causes of death

Mortality in young offenders was higher than in equivalent age groups with schizophrenia or eating disorders

Young offenders accounted for a quarter of drug related deaths in 15-19 year old men

6 Harris EC, Barraclough B. Excess mortality of mental disorder. Br J Psychiatry 1998;173:11-53.

Kalland M, Pensola TH, Merilainen J, Sinkkonen J. Mortality in children registered in the Finnish child welfare registry: population based study. BMJ 2001;323:207-8

8 Oyefeso A, Ghodse H, Clancy C, Corkery J, Goldfinch R. Drug abuse-related mortality: a study of teenage addicts over a 20 -year period. Soc Psychiatry Psychiatr Epidemiol 1999;34:437-41.

9 Thompson SC, Ogilvie EL, Veit FC, Crofts N. Juvenile offenders and hepatitis B: risk, vaccine uptake and vaccination status. Med J Austr 1998; $169: 306-9$

(Accepted 6 March 2003)

\title{
New strategies for increasing the detection of HIV: analysis of routine data
}

James Read, S J Winceslaus

Guy's, King's

College, and

St Thomas's Schoo

of Medicine,

London SE5 9RJ

James Read

final year medical

student

Preston Hall

Hospital, Maidstone

ME17 7NJ

S J Winceslaus

consultant in

genitourinary

medicine

Correspondence to: S J Winceslaus joseph.winceslaus@ mtw-tr.nhs.uk

BMJ 2003;326:1066-7
Despite a gradual increase in the incidence of HIV infection in the United Kingdom over the past decade, ${ }^{1}$ many people with the infection remain undiagnosed. ${ }^{2}$ To increase detection, the Department of Health released the first national strategy for sexual health and HIV in July 2001. ${ }^{3}$ The publication recommended that all people attending genitourinary medicine clinics should be offered an HIV test on their first screening for sexually transmitted infections. Many would agree that this target is impossible to achieve using the prevailing protocol for HIV testing in genitourinary medicine clinics. After consultation with client groups in the Preston Hall clinic, we changed our HIV testing protocol.

\section{Methods and results}

In May 2001 we began offering the HIV test to all clients attending the genitourinary medicine clinic instead of only those who were at high risk or who requested it.

To cope with the anticipated increase in HIV testing without greatly increasing the clinic's workload, we changed the testing protocol. We replaced the detailed oral counselling before testing with a shorter, written explanation of the salient points. These points included a brief explanation of HIV and AIDS and of the "window period" (the first three months of infection, during which the test may not show a positive result); the advantages of the test; and the effect of positive (or negative) results on life insurance. Before testing, clients had to read and sign the information sheet, acknowledging their understanding of and consent to the test.

Using the clinic's quarterly KC60 returns (forms for recording the activity of genitourinary medicine clinics), we compared clinic attendance, number of HIV tests performed, and number of HIV positive diagnoses from 1 April 2001 (a month before the new protocol) to 31 December 2001 with the same data for the three years before 1 April 2001.

The average clinic attendance per quarter increased from 232 to 352 clients, and the average number of HIV tests performed per quarter also increased-from 33 to 130 (table). The proportion of clients who had an HIV test thus rose from 14\% to 
Attendance at genitourinary medicine clinic and uptake of HIV testing, 1 April 1998 to 31 December 2001, with new testing protocol being introduced 1 May 2001

\begin{tabular}{|c|c|c|}
\hline Quarterly periods & $\begin{array}{l}\text { No of tests/No of } \\
\text { clients }\end{array}$ & \% uptake \\
\hline \multicolumn{3}{|l|}{1998} \\
\hline 1 Apr to 30 Jun & $69 / 299$ & 23 \\
\hline 1 Jul to 30 Sep & $47 / 252$ & 19 \\
\hline 1 Oct to $31 \mathrm{Dec}$ & $59 / 263$ & 22 \\
\hline \multicolumn{3}{|l|}{1999} \\
\hline 1 Jan to $31 \mathrm{Mar}$ & $60 / 276$ & 22 \\
\hline 1 Apr to 30 Jun & $43 / 243$ & 18 \\
\hline 1 Jul to 30 Sep & $33 / 202$ & 16 \\
\hline 10 ct to $31 \mathrm{Dec}$ & 9/213 & 4 \\
\hline \multicolumn{3}{|l|}{2000} \\
\hline 1 Jan to 31 Mar & $11 / 119$ & 9 \\
\hline 1 Apr to 30 Jun & $16 / 184$ & 9 \\
\hline 1 Jul to $30 \mathrm{Sep}$ & $20 / 272$ & 7 \\
\hline 1 Oct to $31 \mathrm{Dec}$ & $11 / 214$ & 5 \\
\hline \multicolumn{3}{|l|}{2001} \\
\hline 1 Jan to $31 \mathrm{Mar}$ & $18 / 249$ & 7 \\
\hline 1 Apr to 30 Jun & $107 / 336$ & 32 \\
\hline 1 Jul to 30 Sep & $138 / 366$ & 38 \\
\hline $10 \mathrm{ct}$ to $31 \mathrm{Dec}$ & $145 / 353$ & 41 \\
\hline
\end{tabular}

During 1 April to 31 December 2001, three cases of HIV infection were diagnosed, compared with no cases during 1 April 1998 to 31 March 2001.

$37 \%$. Three cases of HIV infection were diagnosed from 1 April to 31 December 2001, compared with no cases diagnosed in the preceding three years (table).

\section{Comment}

By modifying our HIV testing protocol, we more than doubled the rate of testing among clients attending our genitourinary medicine clinic.

The reasons that attendance increased in the quarter in which the protocol was changed are complex as similar changes were seen nationally. The changes are due partly to increased referrals to the genitourinary medicine services (after publication of the national strategy for sexual health and $\mathrm{HIV}^{3}$ ) and to the public's response to the reported national increase in sexually transmitted infections.

Many young people attending our clinic, however, do so after hearing about us from friends and peers. We therefore feel that such publicity about the "user friendly" local services that the new HIV testing policy had generated could also have contributed to attracting more clients.

Although our clinic has now achieved the Department of Health's 2004 target for HIV testing-that $40 \%$ of patients attending genitourinary medicine clinics should receive the test-we still need to identify the factors preventing some clients from taking up the test.

The increase in attendance and testing also led to an increase in the number of HIV cases diagnosed. Two of the three cases were in women considered to be at low risk of infection; these women would not have been tested under the old system, thus delaying diagnosis.

Overall, we are satisfied with the outcome of our new policy for HIV testing and detection and recommend it to other clinics.

JR is now a house physician at the Kent and Sussex Hospital, Tunbridge Wells.

Contributors: JR was responsible for collecting, critically analysing, and interpreting all the data and for writing the report. SJW planned, designed, and implemented the new protocol, revised the paper, and approved the final version. SJW will act as guarantor.

Competing interests: None declared.

Funding: No special funding.

1 Public Health Laboratory Service, Department of Health and Social Services and Personal Services, Scottish Information and Statistics Division(D)5 Collaborative Group. Trends in sexually transmitted infections in the United Kingdom, 1990 to 1999. London: PHLS, 2000.

2 Public Health Laboratory Service, Department of Health and Social Services and Personal Services, Scottish Information and Statistics Division(D)5 Collaborative Group. PHLS epidemiology of HIV and AIDS. Livision(D)5 Collabor PHLS, 2001

London: PHLS, 2001. London: DoH, 2001. (www.doh.gov.uk/nshs/strategy.htm)

(Accepted 1 April 2003)

\section{Medicine in the time of SARS}

When asked why they became a doctor, some elite beings may be able to reply, "To make a difference," with a straight face, but most ordinary mortals find it difficult to articulate their nebulous reasons without feeling awkward or boring the questioner. Why endure long hours, stress at work, indifferent working conditions, abusive patients, and, now, risk of serious infection? To date, a quarter of the 1268 people with severe acute respiratory syndrome (SARS) in Hong Kong are nurses, doctors, radiographers, and auxiliary staff. One general practitioner has died, and a pregnant intensive care nurse also has atypical pneumonia; the antiviral drug ribavirin is teratogenic.

For readers of Chinese literature, part of the reason for choosing medicine as a vocation may lie in the works of Lu Xun, who recognised the power of fiction to influence lives and inform opinion. Lu Xun was the pen name of Zhou Shouren, a major literary figure who had attended medical college in Sendai, Japan. (In the West, Han Suyin and Adeline Mah are well known minor writers who were also practising physicians.) In his work Lu Xun confronted the failures inherent in Confucianism and the failure of Chinese society to tackle social injustice, illiteracy, and ignorance. Writing in the preface to the anthology of short stories Call to Arms, he recalled having to pawn household items in order to obtain prescriptions for his father. The herbal drugs were useless, and his father died. In his short story Medicine a poor family resorts to desperate measures to treat a young man with tuberculosis because there is no other choice; in Tomorrow a mother takes her 3 year old son to see an indifferent and expensive traditional herbalist, to no avail, and the child dies. Modern medicine represented a force for change and good at the time these pieces were written in early 20th century China.

SARS has changed the way we practise medicine today. Face masks have to be worn by both doctor and patient in the clinic, and every consultation is potentially hazardous. More than ever, we need to hold on to the values that $\mathrm{Lu}$ Xun regarded so highly-fortitude, compassion, and the courage to face unpleasant truths.

Andrew C F Hui senior medical officer, Department of Medicine, Prince of Wales Hospital, The Chinese University of Hong Kong, Hong Kong, SAR, China 